Food Manufacturing Industries Research Association extended its study of the melting and crystallizing behaviour of cocoa butter and of possible alternative fats; and the Fruit and Vegetable Canning and Quick Freezing Research Association continued its work on the effect of conditions of cutting and drying of harvested peas on their texture when canned as processed peas.

Steady progress was made by the British Gelatine and Glue Research Association in fundamental investigations into the structure, properties and mode of formation of gelatin and animal glue; and the Hosiery and Allied Trades' Research Association's investigations on crimped nylon products promise to facilitate a more precise control of their 'handle' and elastic properties. The permanent fireproofing process developed in the British Jute Trade Research Association's Laboratories retains its effectiveness even after immersion in sea water for four to five weeks and also after four months free exposure to atmospheric conditions. Further work by the British Launderers' Research Association has confirmed the effect of traces of impurities in the fibres on the extent of dirt removal produced by detergent solutions. A method recently developed in the British Non-Ferrous Metals Research Association's laboratories allows the fatigue limit of many materials to be determined in a few hours with only one specimen, and the Association has also developed the use of the direct-reading spectrograph, the quantograph, in the analysis of copper and copper alloys. The Research Association of British Paint, Colour and Varnish Manufacturers is using autoradiography to examine the migration of plasticizer from synthetic latex paint films into wooden substrates, and continued a special programme on the adhesion of paint films to their substrates.

The work of the British Paper and Board Industry Research Association is making a material contribu. tion to scientific knowledge of the physical structure of papermaking fibres which it is hoped will lead to improved techniques for developing the physical characteristics in commercial pulp required to produce sheets of paper of satisfactory quality. A main object of the packaging research of the Printing, Packaging and Allied Trades Research Association is to improve the performance of packages so that they provide the maximum protection at the minimum cost. The British Rayon Research Association made further fundamental studies on the frictional properties of individual fibres with particular reference to the effect of diameter. The electromagnetic method of thickness-gauging devised by the British Scientific Instrument Research Association for use on lead-covered power cables has reached the stage of commercial exploitation.

The wide range of the contribution to industrial advance and to national welfare which the Depart. ment of Scientific and Industrial Research is making, both directly through its own research stations and indirectly through its support of the research associations and of fundamental research at the universities, is sufficiently illustrated by the foregoing examples. What should be no less apparent is that the real difficulty is to select from the many possible projects those on which public money can be spent to the best advantage. The increased provision made for the work of the Department over the past few years has not, in fact, permitted any real expansion: it. has scarcely balanced the mounting costs of research. While the present report does not supply all the information required for a sound judgment, it does indicate the need for some careful consideration of the exact functions of the Department and of its place in the national organization of research when the Bill now before Parliament to change its administrative and financial arrangements is debated.

\title{
DETECTION AND DEVELOPMENT OF SCIENTIFIC ABILITY
}

$\mathrm{O}$ N March 17, the British Social Biology Council held a conference on "Scientific Ability: its Detection and Development" at the London School of Economics. It was attended by a good number of teachers, representatives of Government departments, members of national organizations of a scientific nature, and representatives of industry. The purpose of the conference was to consider the influences acting on the minds of boys and girls in deciding whether or not to take up science; the ways in which scientific ability may be detected and developed; and the extent to which originality in science is subject to changing conditions. It brought to light three major points.

The first point was that although science is rapidly altering the material fabric of the economic world, and profoundly influencing all aspects of human culture, very little consideration is being given, at research level, to the nature of scientific ability itself and the conditions under which it develops. This is particularly true of Great Britain. Studies made in the past, chiefly in the United States, have little value in predicting scientific talent, since they fail to distinguish promise in this direction from that in other walks of human life, such as commerce, the arts and the professions. There is urgent need for new researches to be undertaken, drawing on the insights provided by recent progress in psychology.

The second point was that while latent intelligence is almost certainly inherited-a point that received no consideration at the conference-it is now fairly generally agreed that the manner in which it manifests itself is subject to influences of a personal and social nature. There does not appear to be any special mental characteristic that is essential for success in science; instead, given equal degrees of intelligence, the difference between the scientist and the artist, the teacher and the man of affairs, can be attributed to the accidents of family upbringing, educational training, and opportunities in the choice of a career. This realization carries with it a supplementary one that in varying degrees, depending on innate intelligence, there is still in the nation a large reservoir of potential scientific ability lying latentboth among boys, and to a still greater extent among girls, among whom its development presents special difficulties.

A third point was that owing to social pressures, tendencies that are recognized as being unfavourable continue in operation, on account of the absence 
of positive action to resist them. It was, for example, generally agreed that specialization ought not to take place in the schools until a boy or girl has reached the Ordinary level of the General Certificate of Education; but some of those present explained that they were powerless to resist the demands of parents who wanted their children to have the longest possible time in which to prepare for highly competitive examinations. Yet as a measure of attainment, the General Certificate of Education examination itself came in for criticism. At a later stage the same kind of pressures were seen to be exerting a bad effect on work done in polytechnics and similar institutions, the overcrowded syllabus leaving the students no time to pursue their own interests and investigations. These pressures will continue until a concerted effort is made to alter the character of examinations like those for the General Certificate of Education at Ordinary and Advanced level, the First M.B. and for university scholarships, so as to give less weight to the mere accumulation of knowledge that a candidate can carry in his head.

Prof. N. F. Mott opened the proceedings by emphasizing that the function of a university was to give specialized training of a high degree. He felt that in a cultural sense, breadth depended on studying some subject thoroughly and then seeing where it led. But he was aware of the dangers of excessive formalized teaching, and in favour of postponing some of it to courses leading to the Ph.D. degree. He felt compelled to recognize that, under present conditions, a certain amount of specialization at school was unavoidable.

Discussing the nature of seientific ability, Mr. Alec Rodger explained that it took a variety of different forms and that lines of demarcation were indistinct. After reviewing the studies that have been made of this problem, he thought that one might conclude that, in favourable circumstances, any reasonably able person might become a reasonatily competent scientist (though he made an exception in the case of high ability amounting to genius); and since it appeared that general ability was convertible, he drew the conclusion that, in the schools, early specialization in any direction should be resisted. He put forward the suggestion that since young children are keen observers, it might be advisable to build up early training in science around some agriculture instead of the traditional chemistry and physics.

Mr. M. A. Brimer, of the National Foundation for Educational Research, also emphasized the unreliable nature of qualities which in the past had been held to be indicative of ability in science. Those that might be of value in the selection of a young scientist might prove of little reliability in assessing the capabilities of a mature research worker. Throughout the country there was no uniformity in the selection test at $11+$ years of age, on the results of which children were transferred to grammar schools. The seme was true of the test at $13+$ years, upon which allocations were made to technical schools. $\mathrm{H}_{\Theta}$ criticized the General Certificate of Education examination, which was allowed to take place without any check on its reliability; it covered a narrow range of attainment and had only a restricted scope. Basing his case on the argument that the variety of patterns of experience depended on the size of a school, he was in favour of comprehensive schools, and felt that the new ones to be built should be larger than those now in existence. Mr. Brimer suggested that in the schools guidance should be individual and continuous; he looked forward to this development as an essential part of the educational service, carried out by staff specially trained in psychometrics.

Problems relating to the teaching of girls were considered by Dr. E. M. Delf-Smith. Speaking generally, girls' schools experienced acute difficulties on account of the shortage of scientifically trained teaching staff, inadequate laboratory space and a poor supply of equipment. All this, she thought, constituted a great handicap for the nation, not only in a material sense, of girls being lost to science, but also in that conditions were allowed to continue which fostered an outlook on life that lacked a proper appreciation of the cultural value of science. She recognized that it was easier for girls to win places to universities in arts than in science, and that, as a whole, girls showed greater aptitude for biology than for physics; even so, if full use were made of their latent abilities, they would release men for work in the more technical fields, such as engineering.

For the afternoon session, Prof. R. M. Barrer was in the chair. He referred to the number of first-year men at the universities who appeared to have reached the upper limit of their capacity. They constituted a problem in selection, yet all forms of ability were needed by the nation. For success in science, however, certain personal characteristics were also essential, a point that, in his day, Faraday had appreciated.

Drawing on many years of teaching practice under school conditions, Mr. W. Llowarch, of the University of London Institute of Education, said that the most gifted young scientists that had passed through his hands had not fitted into any normal pattern of training; they had demanded individual attention. Yet a considerable proportion of them had elected to take up engineering although they had shown promise of being capable, after suitable training, of undertaking fundamental research. Teaching practice in the schools was still preoccupied with the factual and informational aspects of science, leaving too little time for independent inquiry. The good secondclass boy, he thought, might have his interest aroused best if the approach were made through engineering or agriculture.

Mr. W. H. Dowdeswell, of Winchester College, said that observation and originality were the sparks that shone most brightly in a young scientist. All children were born experimenters; they rebelled against repetition and loved to pursue inquiries to which there was no known answer. Because of that, there was a wide difference in practical work between experiment and verification. He considered that for some of the most gifted boys, the last one or two terms at school, after the scholarship examination, were extremely valuable, providing the opportunity for ranging widely and pursuing individual lines of investigation. For non-scientists, he mæde a strong case for a course in general science at a late school stage. For similar, but still stronger, reasons he made a plea for the introduction of courses in Science Greats at the universities.

The discussion producod a convincing statement from Mr. A. J. Peters, of the National Foundation for Educational Research, on the need for more technical training. A survey on which he had been engaged had shown that the supply of pure scientists was comparatively good but that there was a serious shortage of technologists and technicians. Present 


\section{№. 4514 May 5, 1956}

school courses in chemistry and physics did not appeal to many boys willing and capable of taking up these occupations; and owing to the lack of adequate facilities, thousands of children in secondary modern schools were being lost to British industry. At the grammar school level, too, the lack of suitable equipment for training in applied science was almost universal. In suggesting that considerable scope remained for increasing the supply of young scientists, he was strongly supported by some other speakers, who considered that existing standards of requirements for entrance to industry should be critically examined and courses of training carefully reviewed.

As a whole, however, the discussion served to reveal once more the short range and empirical nature of the terms in which educational matters, and those relating specifically to training in science, are being considered not only by teachers but also by representatives of industry, members of public bodies and by many people at the universities, including a high proportion of scientists. These terms are not adequate for the effective assessment of the problems with which we are faced; still less can they be relied on to produce any satisfactory solution. A wider appreciation of the importance of fundamental research is essential, and with it must be associated a deeper understanding of the part that social forces play in the development and expression of all kinds of human ability. This is the only way in which, at this stage, the supply of scientists can be substantially increased. Only then will science take its true place in the cultural life of the nation.

\section{OBITUARIES}

\section{Prof. W. H. Keesom}

Prof. W. H. Keesom, whose death occurred in Leyden on March 3, was born on June 21, 1876, the son of a farming family at Texel, which is one of the small islands in the north of Holland. On this island the majority of the habitants make their living by lamb breeding. During many years the father of Prof. Keesom was a well-known figure on the lamb market of Leyden, which he regularly visited to deliver his lambs. His origin from the north established a strong impress on the personality of Keesom. So he was tenacious, but 'silent' and difficult in conversation. Also from his origin the young Keesom was not prepared to become a specialist in physics. Because of his unusual intelligence, his parents sent him to Alkmaar to study there at the secondary school.

At the age of eighteen, Keesom started to study at the University of Amsterdam. There he followed the courses of van der Waals and van 't Hoff. It was under the influence of those great masters that Keesom's interest for physics appeared.

In 1900 Keesom left the University of Amsterdam and became assistant under Kamerlingh Onnes at the Physical Laboratory of the University of Leyden. There he worked for seventeen years $(1900-17)$, first as assistant and later as conservator, under the direction of Kamerlingh Onnes on the thermodynamic properties of gases and specially of helium. In 1904 he obtained his doctorate under van der Waals at the University of Amsterdam with a thesis entitled "Isotherms of Mixtures of Oxygen and Carbon Dioxide". In 1912 there appeared his famous paper "Die Zustandsgleichung", in the "Encyclopädie der Mathematischen Wissenschaften".

Keesom left Leyden in 1917 to become lecturer and later professor in the University for Veterinary Science in Utrecht. There he developed a laboratory for X-ray analysis of the structure of solidified gases. In 1923 he returned to Leyden as successor to Kamerlingh Onnes, and since 1924 he had, with Prof. W. J. de Haas, directed the Kamerlingh Onnes Laboratory there. From that date the laboratory was divided into two sections (I and II): Keesom undertook the directorship of section I, which was specially devoted to the study of molecular physics; de Haas took for his part the field of magnetism.

After the success obtained by Kamerlingh Onnes in liquefying helium, the remaining programme con- sisted in making a systematic study of the physical properties of liquid helium. So Keesom started to study, with Wolfke, the dielectric constant of liquid helium. With Clusius, and later with his daughter Annie, he measured the specific heat of liquid helium. It is well known that those measurements led Keesom to the detection of the two phases of liquid helium, helium I and helium II. Just before 1926, Keesom had succeeded in solidifying holium. Also, in his attempts to obtain still lower temperatures, Keesom, together with Gaede, succeeded in 1932 in reaching a temperature of $0.7^{\circ} \mathrm{K}$. by pumping off liquid helium. During his systematic study of the specifie heat of metals and in particular of superconducting metals, Keesom detected with Dr. Kok the jump in the specific heat of tin.

Apart from his two famous discoveries, namely, the $\lambda$-point of liquid helium and the jump in the specific heat of superconducting metals, Keesom and his collaborators carried out a lot of important work in the field of molecular physics. Thus I may mention his systematic work on van der Waals forces by means of measurements on the equation of state, the vapour pressure curve of helium, adsorption of gases, viscosity of gases and liquid helium, the structure of condensed and solidified gases, etc.

To close his scientific career Keesom wrote his book "Helium", which contains essentially a complete report of his life-work on helium in the three states. It is also necessary to mention the important part played by Keesom in the organization of the Institut International du Froid and in the preparation for its international meetings. His various collaborators during those exciting times will remember the way in which he stimulated everybody to write their reports for those meetings. He liked to feel that the outside scientific world should be impressed by the work done at Leyden.

The Second World War stopped Keesom abruptly in his scientific work. As a consequence of the tragic events of those times, Keesom began to suffer from neurasthenia, an illness which had attacked him earlier, after the death of his first wife. He retired from the University of Leyelen in 1945.

During recent years, Keesom had recovered intellectually and again found some interest in scientific problems, which he discussed with his son Piet, professor of physics in the University of Purdue, 